Published in final edited form as:

J Cardiovasc Pharmacol Ther. 2018 September ; 23(5): 387-398. doi:10.1177/1074248418769612.

\title{
The Impact of Pazopanib on the Cardiovascular System
}

\author{
Cody N. Justice, BS ${ }^{1}$, Mohamed H. Derbala, MD ${ }^{1}$, Tesla M. Baich, BS ${ }^{1}$, Amber N. Kempton, \\ BS $^{1}$, Aaron S. Guo ${ }^{1}$, Thai H. Ho, MD, PhD², and Sakima A. Smith, MD, MPH ${ }^{1,3}$ \\ ${ }^{1}$ Davis Heart and Lung Research Institute, The Ohio State University, Columbus, $\mathrm{OH}$, USA \\ ${ }^{2}$ Mayo Clinic Scottsdale, Arizona, Phoenix, AZ, USA \\ ${ }^{3}$ Division of Cardiology, Department of Internal Medicine, The Ohio State University College of \\ Medicine, Columbus, $\mathrm{OH}$, USA
}

\begin{abstract}
Pazopanib is an approved treatment for renal cell carcinoma and a second-line treatment for nonadipocytic soft-tissue sarcoma. However, its clinical efficacy is limited by its cardiovascular side effects. Pazopanib and other vascular endothelial growth factor receptor tyrosine kinase inhibitors have been associated with the development of hypertension, QT interval prolongation, and other cardiovascular events; however, these mechanisms are largely unknown. Gaining a deeper understanding of these mechanisms is essential for the development of appropriate surveillance strategies and possible diagnostic biomarkers to allow us to monitor patients and modulate therapy prior to significant cardiac insult. This approach will be vital in keeping patients on these life-saving therapies and may be applicable to other tyrosine kinase inhibitors as well. In this review, we provide a comprehensive overview of the preclinical and clinical side effects of pazopanib with a focus on the mechanisms responsible for its toxicity to the cardiovascular system.
\end{abstract}

\section{Keywords}

renal cell carcinoma; hypertension; pazopanib; tyrosine kinase inhibitors

Reprints and permission: https://www.sagepub.com/journalsPermissions.nav

Corresponding Author: Sakima A. Smith, The Ohio State University Wexner Medical Center, 473 West 12 th Ave, Suite 200, Columbus, OH 43210, USA. sakima.smith@osumc.edu.

Authors' Contribution

C. N. Justice contributed to conception, design, acquisition, analysis, and interpretation; drafted the manuscript; critically revised the manuscript; gave final approval; and agrees to be accountable for all aspects of work ensuring integrity and accuracy. M. H. Derbala, T. M. Baich, and A. N. Kempton contributed to design, acquisition, analysis, and interpretation; drafted the manuscript; critically revised the manuscript; gave final approval; and agrees to be accountable for all aspects of work ensuring integrity and accuracy. A. S. Guo contributed to acquisition, analysis, and interpretation; critically revised the manuscript; gave final approval; agrees to be accountable for all aspects of work ensuring integrity and accuracy. T. H. Ho contributed to conception, design, acquisition, analysis, and interpretation; drafted the manuscript; critically revised the manuscript; gave final approval; and agrees to be accountable for all aspects of work ensuring integrity and accuracy. S. A. Smith contributed to conception, design, acquisition, analysis, and interpretation; drafted the manuscript; critically revised the manuscript; gave final approval; and agrees to be accountable for all aspects of work ensuring integrity and accuracy.

Declaration of Conflicting Interests

The author(s) declared no potential conflicts of interest with respect to the research, authorship, and/or publication of this article. 


\section{Introduction}

Kidney cancer is the 16th most common cause of death worldwide. ${ }^{1}$ Renal cell carcinoma (RCC) accounts for approximately $90 \%$ of all cases with kidney cancer with an estimated 337800 diagnoses and 143000 deaths per year worldwide. ${ }^{1}$ The incidence and prevalence of RCC have been increasing over the last 50 years, and with the growth of the US elderly population, these numbers are only expected to continue to increase. Renal cell carcinoma is particularly morbid, and the overall 5-year survival rate of metastatic RCC is approximately $12 \% .^{2}$

The incidence rate of RCC is highest among those $>70$ years of age, males, African Americans, and Hispanics. ${ }^{2}$ Notably smoking is an independent risk factor for RCC development and individuals smoking $>30$ to 40 pack-years are $80 \%$ more likely to develop advanced RCC. ${ }^{2}$ A $5-\mathrm{kg} / \mathrm{m}^{2}$ increase in body mass index increases the risk of developing RCC by over $20 \% .{ }^{1}$ Of note, other risk factors for the development of RCC include hypertension (HTN), dialysis, and genetic disorders such as Von Hippel Lindau syndrome, hereditary papillary RCC, and Birt-Hogg-Dubé syndrome (characterized by multiple benign skin tumors, lung cysts, and a predisposition for kidney neoplasms). ${ }^{2,3}$

The vascular endothelial growth factor (VEGF) pathway plays an important role in tumor growth and angiogenesis. ${ }^{4}$ Pazopanib, a VEGF inhibitor, is approved by the Food and Drug Administration (FDA) as a first- and second-line treatment for late stages of RCC and nonadipocytic soft-tissue sarcoma (STS), respectively. ${ }^{5,6}$ Pazopanib provides a higher quality of life and lower incidence of side effects compared to other VEGF inhibitors. ${ }^{7}$ Despite its efficacy in RCC treatment, pazopanib can also cause a variety of adverse reactions including gastrointestinal upset, hypothyroidism, bone marrow toxicity, HTN, heart failure (HF), myocardial ischemia, and arterial thromboembolic events (Table 1). ${ }^{11}$ These side effects may be attributed to inhibition of intended kinases (on-target inhibition) or nonspecific inhibition of unintended kinases (off-target inhibition) ${ }^{12}$ which is discussed later in this review.

The cardiovascular side effects of pazopanib are especially concerning because cardiovascular comorbidities are common in patients with RCC (cancer and cardiovascular disease share many common risk factors). ${ }^{13}$ Hence, the goal of this review is to gain a deeper understanding regarding the fundamental relationship between pazopanib and its cardiovascular side effects that may improve the treatment of RCC in the long term.

\section{Pharmacology/Pharmacokinetics}

Pazopanib is one of several tyrosine kinase inhibitors (TKIs) that have been FDA approved to treat metastatic RCC and advanced STS. ${ }^{14}$ Small-molecule TKIs, including pazopanib, inhibit the activity of various receptor tyrosine kinases by competitively inhibiting Adenosine triphosphate (ATP) binding to the intracellular ATP-binding pocket. ${ }^{14}$ Pazopanib contains an adenine-like ring that mimics the hydrogen bonding capability of ATP to several kinases and inhibits VEGF receptors, platelet-derived growth factor (PDGF) receptors, and stem cell factor receptors. ${ }^{14}$ Pazopanib inhibition of VEGF signaling is primarily 
responsible for its antiangiogenic effects on tumor growth. Additionally, pazopanib inhibits other kinases such as fibroblast growth factor receptors 1 and 3, interleukin 2 receptorinducible T-cell kinase, leukocyte-specific protein tyrosine kinase, and transmembrane glycoprotein receptor tyrosine kinase. ${ }^{15}$ The ATP-binding pocket is highly conserved across the kinome,${ }^{16}$ allowing drugs such as pazopanib to serve as "multikinase" inhibitors. Notably multitargeting contributes to the efficacy of cancer treatments; however, this inherent lack of selectivity may underlie its cardiovascular toxicity.

Pazopanib is commercially available in 200 and $400 \mathrm{mg}$ oral tablet forms. ${ }^{14}$ The recommended dose is $800 \mathrm{mg}$ taken once daily an hour before or 2 hours after food consumption. ${ }^{14}$ Pazopanib takes 2 to 4 hours to reach peak absorption with a half-life of 30.9 hours, making daily dosing adequate for steady-state concentration. ${ }^{14}$ The mean area under the concentration curve achieved at this dosage is $1037 \mathrm{~h} \mathrm{mg} / \mathrm{mL}$ with a $\mathrm{C}_{\max }$ of 58.1 $\mu \mathrm{g} / \mathrm{mL} .{ }^{14}$ For patients with RCC, tumor shrinkage and progression-free survival are correlated with a sustained plasma concentration of at least $20.5 \mu \mathrm{g} / \mathrm{mL}$ over the course of treatment as assessed by Ctrough. Plasma concentration thresholds above this value do not provide an additional benefit and may increase toxicity. ${ }^{17}$

It is advised that concurrent use of CYP3A4 inhibitors be avoided when on a pazopanib treatment regimen, as they may cause an increase in drug levels and lead to toxicity. ${ }^{14}$ Dosage should be decreased to $400 \mathrm{mg}$ daily if CYP3A4 inhibitors cannot be avoided. ${ }^{14}$ Dosage may be decreased from 800 to $400 \mathrm{mg}$ or $200 \mathrm{mg}$ in patients who exhibit doselimiting toxi-city. ${ }^{18}$ Therapeutic levels are achievable in these patients at lower dosages due to high interpatient variability regarding drug absorption and metabolism. Recent clinical trials are investigating pharmacokinetically guided dosing of pazopanib to account for this variability and optimize treatment. ${ }^{19,20}$

\section{Specific Cardiovascular Adverse Effects Associated With Pazopanib}

The cardiovascular toxic effects of targeted therapies represent a challenge in oncologic care that can drain patients emotionally and physically. Cardiovascular side effects lead to significant morbidity and mortality in patients with cancer and survivors. ${ }^{21}$ Improving our fund of knowledge regarding cardiovascular side effects together with early intervention and surveillance will help contribute to improved clinical outcomes in both patients with cancer and survivors.

\section{Hypertension}

Hypertension is the most frequently observed cardiovascular adverse event in patients treated with anti-VEGF agents including pazopanib for metastatic RCC. ${ }^{8,22-24}$ Hypertension is associated with an increased risk of stroke, myocardial infarction (MI), and $\mathrm{HF}^{25}$ Wildtype mice that received $30 \mathrm{mg} / \mathrm{kg}$ of pazopanib twice daily developed a statistically significant increase in mean arterial pressure compared to control mice after 2 weeks of treatment. ${ }^{26}$ In a randomized, double-blind, placebo-controlled phase 3 clinical trial in patients with advanced RCC, the incidence of HTN was nearly $40 \%$ in patients receiving pazopanib compared to only $10 \%$ in the placebo group. ${ }^{8}$ Thirteen of 250 patients on pazopanib developed grade 3 adverse event $\mathrm{HTN}^{8}$ which was defined according to the 
Common Terminology Criteria for Adverse Events (CTCAE) v3.0 as a recurrent or persistent HTN ( $\geq 24$ hours) or a symptomatic increase by $>20 \mathrm{~mm} \mathrm{Hg}$ (diastolic) or to $>150 / 100$ if previously within normal, in addition to requiring $>1$ medication or more intensive treatment. ${ }^{8}$ Additionally, a phase 3 randomized trial in patients with metastatic RCC that compared pazopanib and sunitinib (a similar TKI) as first-line therapies regarding efficacy and safety demonstrated that there were minimal between-group differences in HTN development. Approximately 257 of 554 and 223 of 548 patients developed HTN with pazopanib and sunitinib, respectively. Likewise, about $14 \%$ of patients in both the pazopanib and the sunitinib arms developed grade 3 adverse event HTN. ${ }^{7}$ Notably, HTN also developed in approximately $37 \%$ of patients with recurrent glioblastoma in phase 2 trial of pazopanib (totaling 35 patients). Hypertension was manageable with antihypertensives and reversible with drug discontinuation. ${ }^{27}$

Previous studies have suggested that HTN potentially serves as a predictive factor for better outcomes in patients receiving TKIs such as sunitinib ${ }^{28-31}$; however, this has yet to be proven for pazopanib. Data from a retrospective analysis based on European Organization for Research and Treatment of Cancer 62043 and 62072 trials in pazopanib-treated patients with advanced nonadipocytic STS has demonstrated that pazopanib-associated HTN had no correlation with progression-free survival and overall survival in these patients. ${ }^{32}$ Further studies are required to properly delineate the viability of using HTN as a biomarker for pazopanib efficacy.

Blood pressure monitoring.-The hypertensive response of pazopanib is rapid and its incidence is correlated with preexisting HTN. When administered at supratherapeutic concentrations ( $800 \mathrm{mg}$ daily on an empty stomach for 7 days and $1600 \mathrm{mg}$ with food for 1 day) in a double-blind, placebo-controlled, parallel-group study, pazopanib led to a clinically significant increase in blood pressure after only 8 days of treatment initiation. Blood pressure levels returned to near normal by 24 hours after the last treatment. ${ }^{33}$ In clinical practice, pazopanib-induced HTN develops in the majority of patients within 4 weeks of starting pazopanib. ${ }^{34} \mathrm{~A}$ recent retrospective analysis of 35 pazopanib-treated patients with advanced/metastatic RCC found that $57 \%$ of the patient cohort (20/35) developed any grade HTN and that more than half of these cases developed within 25 days of starting pazopanib. Preexisting HTN was a risk factor for pazopanib-induced HTN. ${ }^{35}$

In order to mitigate insult to the cardiovascular system, blood pressure should be normalized according to the Eighth Joint National Committee (JNC-8) guidelines prior to starting pazopanib. We would recommend obtaining blood pressure measurements at baseline and after 1 week, 1 month, and 2 months after the initiation of pazopanib. Any increases in blood pressure should be treated according to current guidelines. Pazopanib-induced HTN is generally manageable with antihypertensives and reversible with discontinuation of therapy ${ }^{15,22,35}$; however, a small percentage of patients will require a dose reduction. ${ }^{22,36}$ For these patients, it is recommended that the dosage of pazopanib be reduced incrementally to $400 \mathrm{mg}$ daily and $200 \mathrm{mg}$ daily followed by drug discontinuation in the case of severe HTN that is unresponsive to anti-hypertensive therapy. ${ }^{14,18}$ Due to high interpatient variability in drug absorption and metabolism, ${ }^{22,37,38}$ a higher proportion of patients receiving the minimal available dose of pazopanib $(200 \mathrm{mg})$ may fail to reach optimal 
therapeutic plasma levels (>20.5 $\mu \mathrm{g} / \mathrm{mL})^{17}$; however, we believe that dose reduction is the best course of action in cases of unmanageable HTN.

The optimal choice of antihypertensive medication for these patients remains a subject of ongoing investigation. There are no specific guidelines for the management of HTN induced by anti-VEGF therapy. Hypertension should be managed according to each patient's comorbidities and JNC-8 guidelines with the goal of mitigating cardiac insult and optimizing cancer treatment. Angiotensin converting enzyme inhibitors (ACEIs) and angiotensin II receptor blockers (ARBs) are commonly used for patients on pazopanib. Although it has been proposed that ACEIs and ARBs work synergistically with antiangiogenic therapies to inhibit tumor growth, a survival benefit was not demonstrated in a retrospective study of 35 advanced patients with metastatic RCC who received pazopanib with or without one of these antihypertensive medications. ${ }^{35,39}$ Dihydropyri-dine calcium channel blockers are also commonly used to manage pazopanib-induced HTN; however, nifedipine should be used with caution as it is an inducer of VEGF secretion. ${ }^{40,41}$ Nondihydropyridine blockers such as verapamil and diltiazem are contraindicated with angiogenesis inhibitors due to inhibition of CYP3A4. ${ }^{40,41} \mathrm{~A}$ combination of $\beta$-blockers and hydra-lazine may also be used to manage pazopanib-induced HTN, especially for patients with left ventricular dysfunction or arrhythmia. ${ }^{25,42}$ More prospective clinical studies are needed in order to develop evidence-based treatment guidelines for managing pazopanibinduced HTN.

\section{Potential mechanisms of pazopanib-induced HTN}

Imbalance of vasoconstrictors and vasodilators.-Basal VEGF receptor 2 signaling is believed to inhibit the production of endothelin 1, a potent vasoconstrictor, although the exact mechanism is unknown (Figure 1). ${ }^{43}$ Inhibition of VEGF receptor 2 by pazopanib may lead to increased endothelin 1 levels in circulation, causing sustained vasoconstriction. In rats and humans, levels of circulating endothelin 1 were elevated due to treatment with sunitinib. ${ }^{44}$ In humans, blocking the endothelin 1 receptor resulted in reduced peripheral resistance and improved cardiac output. ${ }^{45-47}$ In rats, pretreatment with an endothelin receptor type A antagonist prevented linifanib-induced rise in blood pressure. ${ }^{44,48}$ These studies demonstrate the impact of endothelin 1 on the cardiovascular system, which can be antagonized by inhibition of VEGF receptor-2. Pazopanib should be scrutinized for its effects on nitric oxide and endothelin-1, as this drug is a potent inhibitor of VEGF receptor 2 (similar to sunitinib).

Capillary rarefaction.-A second proposed mechanism of pazopanib-induced HTN is capillary rarefaction (reduction in capillary density) leading to increased peripheral resistance and afterload. Vascular endothelial growth factor is normally secreted from cardiomyocytes and acts on endothelial cells in a paracrine manner by way of VEGF receptors (Figure 1) ${ }^{49,50}$ It has been demonstrated that paracrine and autocrine VEGF signaling is critical to the maintenance of newly differentiated microvasculature and the proliferation of endothelial cells ${ }^{51-54}$ as well as cardiomyocyte survival. ${ }^{55,56}$ Pazopanib inhibition of VEGF signaling may lead to endothelial dysfunction and regression of capillary networks. Accordingly, reduced capillary density and impaired angiogenesis are 
directly involved in the development of HTN ${ }^{57}$ Therefore, it is possible that the hypertensive effects of pazopanib are due to endothelial cell dysfunction leading to capillary rarefaction.

Direct renal impairment.-A third proposed mechanism of pazopanib-induced HTN is renal impairment leading to activation of the renin-angiotensin-aldosterone system. In addition to the coronary microvasculature, it has been demonstrated that VEGF signaling is vital to the proliferation of renal glomeruli endothelial cells. ${ }^{58-61}$ Therefore, it is expected that pazopanib could lead to capillary rarefaction in renal glomeruli with an increased secretion of renin from the juxtaglomerular apparatus, leading to downstream production of angiotensin II and systemic vasoconstriction. However, no experimental evidence supports this humoral-based hypothesis to date. ${ }^{62}$ In fact, plasma renin levels significantly decreased in rats treated with sunitinib, and the coronary microvasculature in these rodents became less responsive to exogenous angiotensin II. ${ }^{44}$ Sunitinib-induced blood pressure elevation in humans was not accompanied by renal impairment, suggesting that the renin-angiotensinaldosterone system was likely not involved with this mechanism of HTN ${ }^{44}$ In support of this conclusion, treatment of humans with sorafenib did not lead to a change in serum levels of aldosterone, plasma renin, endothelin 1, or urotensin II. ${ }^{63}$ This study concluded that the hypertensive effects of sorafenib are independent of the renin-angiotensinaldosterone system. ${ }^{63}$ However, it is worth investigating the involvement of this mechanism in pazopanib, as each TKI should be assessed on a case-by-case basis considering that the kinase selectivity profile of each TKI is variable ${ }^{64}$ and that pazopanib-induced HTN is generally manageable by treatment with antihypertensives. ${ }^{9,15,22,35}$

\section{QT Interval Prolongation}

Anticancer drug development is a burdensome task that requires many years and billions of dollars, and eventually very few are approved by the FDA. ${ }^{65}$ QT interval prolongation, a cardiac toxicity that increases the risk for the development of malignant ventricular tachyarrhythmias (especially Torsades de Pointes, ventricular fibrillation, and sudden cardiac death), ${ }^{66}$ is the most common reason for FDA delayed/nonapproval or withdrawal of several anticancer drugs. ${ }^{67}$ Numerous VEGF receptor TKIs have been associated with the development of QT interval prolongation. ${ }^{68-70}$ Hence, scrupulous monitoring of QT interval prolongation is mandatory not only to assess the risk of serious cardiac toxicities of anticancerous agents but also to ascertain whether allocating further resources to the development of these agents is worthwhile. ${ }^{65}$

Animal studies have demonstrated that adult male rats given pazopanib showed a QTc interval prolongation of around 30 milliseconds when compared to control animals 3 hours after drug administration $(99.93 \pm 3.62$ milliseconds versus $131.23 \pm 12.21$ milliseconds, respectively; $P<.001) .{ }^{71}$ Notably, metoprolol or diltiazem cotreatment significantly prevented the QT prolonging effect of pazopanib. ${ }^{71}$

The incidence of QT interval prolongation is rare in pazopanib-treated patients compared to other TKI-treated patients. Notably, in sunitinib-treated patients compared to controls, the incidence of QT interval prolongation was $2 \%$ versus $0.2 \%$ respectively, with a relative risk 
of 9.01 (95\% confidence interval [CI] $1.15-70.7 ; P$ value $=.04$ ). Furthermore, the incidence of QT interval prolongation for vandetanib was much higher than controls $(8 \%$ and $1.2 \%$, respectively). ${ }^{10}$ In a phase 3 trial of 435 patients treated with pazopanib, $1 \%$ of the patients developed QT interval prolongation (defined as QT interval 2500 milliseconds) and Torsades de Pointes. However, a trial-level meta-analysis of randomized phase 2 and 3 trials comparing several VEGF receptor TKIs demonstrated that there was no statistically significant increase in the relative risk of QT interval prolongation in pazopanib-treated patients versus controls. The lack of significance of these data might be attributed to the power of the study, as only 2 trials (totaling 804 patients) were pooled in the meta-analysis. $6,8,10$

Although the incidence of pazopanib-induced QT interval prolongation is relatively low, patients with cancer are at an increased risk of prolonged QT interval owing to older age, underlying disease, and concomitant medications. ${ }^{72}$ Furthermore, these patients may experience treatment-associated hepatic dysfunction that impedes drug clearance and metabolism. ${ }^{8,65,73}$ Additionally, diarrhea is one of the most common side effects reported with pazopanib-treated patients $8,22,24$ which could result in QT interval prolongation through electrolyte derangements. ${ }^{74}$ The prescription information for pazopanib recommends precise risk assessment in patients with a history of QT interval prolongation and/or receiving antiarrhythmics with pretreatment of electrolytes if necessary and periodic electrocardiogram (ECG) monitoring. ${ }^{14}$ Pazopanib is currently listed as a drug that can cause QT prolongation, but there is a lack of evidence for the risk of Torsades de Pointes development. ${ }^{75}$

Electrocardiography monitoring.-Due to the incidence of QTc interval prolongation associated with pazopanib and the increased risk of Torsades de Pointes, electrolyte levels should be optimized $\left(\mathrm{K}^{+}>4\right.$ milliequivalents and $\mathrm{Mg}^{2+}>2$ milliequivalents) prior to treatment with periodic assessment of laboratory test results and monthly ECG monitoring. There is a paucity of evidence regarding the correlation between duration of pazopanib exposure and QTc prolongation ${ }^{10}$; however, one double-blind, placebo-controlled study of 96 patients randomized to pazopanib versus moxifloxacin found a concentrationindependent prolongation of the QTc interval that occurred within 9 days of starting pazopanib. ${ }^{33}$ Although this study used supratherapeutic concentrations of pazopanib, we would recommend electrolyte level monitoring and ECG monitoring at baseline and after 1 month of pazopanib treatment. Evidence of QTc prolongation or other ECG abnormalities may warrant a dose reduction in pazopanib with more frequent surveillance.

\section{Potential mechanisms of pazopanib-induced QT interval prolongation.-} Pazopanib was recently found to inhibit downstream enzymes B-RAF ${ }^{76}$ and C-RAF ${ }^{77}$ in an off-target manner (Figure 2), which may be responsible for its effect on systolic function. The RAF kinases are cardioprotective and promote cardiomyocyte growth and survival. ${ }^{78,79}$ Inhibition of these kinases likely contributes to cardiovascular toxicity, as cardiac-specific CRAF knockout mice have increased cardiomyocyte apoptosis accompanied by left ventricular systolic dysfunction and dilation of the heart. ${ }^{80} \mathrm{~B}-\mathrm{RAF}$ activity is a strong mediator of human ether-a-go-go-related gene (hERG) channel expression, ${ }^{81}$ and selective 
inhibition of B-RAF by vemurafenib has been associated with prolonged QT interval in humans. ${ }^{82}$ Mechanistically, it has been proposed that BRAF inhibition may lead to a compensatory increase in cyclic adenosine monophosphate (AMP) leading to overactivation of protein kinase $\mathrm{A}$, an enzyme that phosphorylates hERG channels and reduces their ability to open during action potential voltages-prolonging repolarization period and contributing to prolonged QT interval. ${ }^{79}$ This mechanism was proposed based on the potent inhibition of BRAF by sorafenib. Pazopanib also inhibits this enzyme ${ }^{76}$ in an off-target manner and should be closely scrutinized for modifying hERG channel activity due to the incidence of prolonged QT interval in pazopanib-treated patients.

\section{Heart Failure}

Heart failure and cancer represent 2 major causes of morbidity and mortality in the Western population, imposing a burden on the world economy. ${ }^{82-86}$ The global economic cost of HF in 2012 was approximately US $\$ 108$ billion per annum. ${ }^{83}$ Heart failure is the leading cause of hospitalization each year in the United States and Europe, ${ }^{87-89}$ affecting nearly 5.7 million people in the United States with an incidence of $670000.82,87,90$ Cancer and cardiovascular diseases share many common risk factors, and patients with cancer are more susceptible to develop HF in general. ${ }^{86,91}$ Of note, previous studies have linked VEGF receptor TKIs with HF development. ${ }^{23,92}$

A phase 3 randomized clinical trial that compared pazopanib and sunitinib as first-line treatment for metastatic RCC showed that HF occurred in 11\% (42 out of 548) and 13\% (47 out of 544) of patients receiving pazopanib and sunitinib, respectively. Notably, about half of the patients developed HF with reduced ejection/systolic dysfunction. ${ }^{7}$ Myocardial dysfunction was defined as $15 \%$ absolute decline in left ventricular ejection fraction (LVEF) compared to normal or $\geq 10 \%$ decline in LVEF compared to baseline or the development of cardiac dysfunction symptoms. ${ }^{7}$ The phase 3 randomized clinical trial Pazopanib Versus Placebo in patients with STS whose disease has progressed during or following prior therapy (PALETTE, ClinicalTrials.gov, number NCT00753688) found that 5\% of patients on placebo developed HF compared to $11 \%$ of patients on pazopanib. Myocar-dial dysfunction was defined using the aforementioned criteria except for $\geq 5 \%$ instead of $\geq 10 \%$ decline in LVEF compared to baseline. ${ }^{6}$ In another contemporary study, $6 \%$ and $20 \%$ of patients developed HF and reduced LVEF after receiving pazopanib, respectively. ${ }^{35}$

A recent comprehensive meta-analysis of 36 trials provided some insight into the overall incidence and risk of HF development in different patients with cancer treated with VEGF receptor TKIs. The study concluded that there was a significantly increased risk for the development of HF in patients with cancer treated with VEGF receptor TKIs, and thus these patients should be closely monitored for the development of HF signs and symptoms. ${ }^{12}$ The incidence of all grade HF (defined according the CTCAE v2.0 or v3.0) and high-grade ( zgrade 3) HF in patients receiving pazopanib was 6.1 and 1.5 , respectively. The odds ratio of all grade HF development for the pazopanib subgroup was 2.4 (95\% CI,1.01-5.69; $P$ value $=.047)$ while that of high-grade $\mathrm{HF}$ was $4.52(95 \% \mathrm{CI}, 0.06-299.3: P$ value $=.51) .{ }^{12}$

Interestingly, a recent report of a 47-year-old male patient with metastatic RCC with no significant past medical history showed an improvement in his LVEF from $20 \%$ to $25 \%$ to 
$43 \%$ within 7 months after starting a low dose of pazopanib $(400 \mathrm{mg} / \mathrm{d})$ uptitrated to 800 $\mathrm{mg} / \mathrm{d} .{ }^{93}$ To date, this is the only known case of RCC wherein the patient experienced a significant improvement in cardiac function after pazopanib use and showing good tolerability to pazopanib with an ejection fraction as low as $20 \%$ to $25 \%$, a factor that has limited pazopanib use in similar scenarios. ${ }^{93}$ This raises the question of whether pazopanib use should be precluded in low ejection fraction states or could be used in gradually uptitrated doses..$^{93}$ In line with this, a recent study compared the quality of life and progression-free survival in patients with STS on low-dose pazopanib with the PALETTE phase 3 study. ${ }^{94}$ The study concluded that pazopanib can be initially started at low doses with gradual increments and careful monitoring of side effects. ${ }^{94}$ These data, while intriguing, will need to be confirmed in larger prospective multicenter studies.

The true incidence of HF is unclear, as more prospective studies are needed with accurate cardiovascular monitoring to precisely quantify the incidences of asymptomatic and symptomatic cardiac dysfunction. Moreover, isolated and coexisting right ventricular dysfunction is often unreported because such patients are usually excluded from clinical trials. ${ }^{95}$ The American College of Cardiology/American Heart Association guidelines state that patients with cancer having HF should be managed with standard HF therapies regardless of their cancer status. ${ }^{96}$ Patients should be closely monitored for the development of clinical signs and/or symptoms of HF in addition to pretreatment and periodic ontreatment assessments of LVEF, particularly high-risk patients and those with a history of anthracycline use. ${ }^{11,95}$

Echocardiography monitoring.-Periodic echocardiography monitoring of patients on pazopanib may prove to be a useful method for detecting early signs of cardiotoxicity. A recent retrospective study that followed 23 patients with metastatic RCC treated with a TKI (pazopanib [65\%], sunitinib [26\%], or axitinib [9\%]) demonstrated that change in left ventricular strain (an early indication of systolic dysfunction) $)^{97,98}$ may indicate early signs of TKI-induced cardiotoxicity. However, these results must be confirmed in a longer term study and correlated with reduction in LVEF. ${ }^{11}$ Interestingly, the study found that the right ventricle is more vulnerable to chemotherapy (in the absence of pulmonary HTN) than the left side which may be due to its thinner wall. ${ }^{11}$ Notably right-sided HF is often underreported because these patients are excluded from clinical trials. ${ }^{95}$ Therefore, we recommend close echocardiogram surveillance of all patients receiving pazopanib at baseline, 1 month, and 3 months, and any abnormalities may warrant a dose reduction.

Potential mechanisms of pazopanib-induced systolic dysfunction.-Fibroblast growth factor signaling in the heart is essential for normal physiologic processes. ${ }^{99,100}$ Notably, pazopanib inhibition of fibroblast growth factor receptor 1 may be responsible for its adverse effects on systolic function, as this receptor may have a role in contractility. Acute expression of this receptor increases cardiomyocyte contractility and chronic expression leads to significant cardiomyocyte hypertrophy and preservation of systolic function. ${ }^{101}$ By this mechanism, pazopanib-induced systolic dysfunction may be a result of off-target inhibition of fibroblast growth factor receptor 1 . Therefore, it will be worthwhile 
to determine whether pazopanib perturbs cardiomyocyte contractility and whether this effect is due to inhibition of fibroblast growth factor receptor 1.

Furthermore, VEGF blockade causes endothelial dysfunction and transition from physiological to pathological hypertrophy, a process that if prolonged leads to dilated cardiomyopathy and end-stage HF. ${ }^{102-104}$ Additionally, PDGF receptor- $\beta$ signaling in the myocardium plays a critical role in stress-induced coronary angiogenesis. ${ }^{105}$ Sunitinibinduced dysfunction of the coronary microvasculature was attributed to the inhibition of PDGF receptor- $\beta$ signaling in pericytes. ${ }^{106}$ Therefore, it is possible that pazopanib treatment leads to pathological hypertrophy due to its ability to inhibit these key proangiogenic pathways.

\section{Myocardial Ischemia, Apoptosis, and Thrombosis}

Myocardial infarction is a leading cause of death in the United States with an incidence of approximately 580000 new cases and 210000 recurrent attacks each year. ${ }^{107}$ From 2000 to 2010, the number of hospital discharges for coronary heart disease was about 1340000 with direct and indirect costs estimated at US $\$ 10.4$ billion which are expected to double by 2030. ${ }^{108}$ Recent studies have associated pazopanib with the onset of MI. In a phase 3, placebo-controlled trial in patients with meta-static RCC and STS, the incidence of treatment-related MI/ischemia was about $2 \%^{8}$ and $1 \%$, respectively (ClinicalTrials.-gov Identifier: NCT00753688). In addition, cerebrovascular accidents and transient ischemic attacks occurred in $<1 \%$ of pazopanib-treated patients with metastatic RCC. ${ }^{8}$ Likewise, thrombosis developed in $<1 \%$ of patients receiving pazopanib for advanced and recurrent cervical cancer. ${ }^{108}$ Furthermore, venous thromboembolic events were reported in 5\% of the patients with STS on pazopanib. ${ }^{6}$ Therefore, despite the low incidence of thromboembolic events and acute MI development reported with pazopanib, it should be used with caution in patients with history of coronary artery disease, previous embolic stroke, or at high risk of thromboembolic events. ${ }^{14}$

Potential mechanisms of pazopanib-induced myocardial ischemia, apoptosis, and thrombosis.-Vascular endothelial growth factor signaling is vital for endothelial cell proliferation and coronary angiogenesis secondary to stretch-induced cardiac hypertrophy $56,102,104,109$ as well as cardiac remodeling after ischemicinjury. ${ }^{55}$ Even in nonpathologic states, autocrine VEGF signaling is essential to endothelial cell survival (Figure 1). ${ }^{53}$ Pazopanib may be responsible for apoptosis of endothelial cells, which are prone to coagulation ${ }^{110-112}$ and may be responsible for thromboembolic and ischemic events in pazopanib-treated patients. Pazopanib inhibition of VEGF signaling may also increase blood viscosity through overproduction of erythropoietin, exacerbating risk for thrombosis. ${ }^{113,114}$

Normal fibroblast growth factor signaling in the heart is vital for cell proliferation, differentiation, survival, and angio-genesis. ${ }^{99,100}$ Fibroblast growth factor 2 knockout mice develop thrombocytosis, poor vascular function, and an impaired cardiac ability to hypertrophy in response to ischemic ${ }^{115}$ and pressure overload conditions. ${ }^{116}$ These studies demonstrate the importance of fibroblast growth factor signaling in the heart, which may be 
adversely affected by pazopanib. This inhibition may significantly contribute to the hypertensive and anti-angiogenic properties of pazopanib, as well as apoptosis, endothelial cell dysfunction, and pathological remodeling.

In addition to its effects on endothelial cells, pazopanib inhibition of the receptor tyrosine kinase/phosphoinositide 3-kinase (PI3K)/protein kinase B (AKT) pathway may lead to activation of cardiomyocyte apoptotic pathways, as AKT is responsible for inactivating $\mathrm{BAD}$, a proapoptotic protein. ${ }^{117,118}$ In the heart, AKT activation reduced cardiomyocyte apoptosis and drastically preserved cardiac function in an ischemic rat model. ${ }^{119}$ In mice, activation of the PI3K/AKT/mechanistic target of rapamycin pathway prevented adriamycininduced cardiomyocyte apoptosis and autophagy. ${ }^{120} \mathrm{In}$ a rabbit model of pressure overload, exogenous VEGF prevented cardiomyocyte apoptosis and preserved cardiac function, ${ }^{121}$ possibly through improved VEGF receptor-2/PI3K/AKT regulation of Bcl-2 proteins. These studies implicate the cardiomyocyte-protective role of PI3K/AKT signaling during cardiac stress. However, while pazopanib is a potent inhibitor of VEGF receptor-2 and other receptor tyrosine kinases, it may not necessarily lead to cardiomyocyte apoptosis in patients, as the PI3K/AKT pathway is activated by many factors in the heart, ${ }^{122}$ several of which are spared by pazopanib. Furthermore, VEGF may contain receptor-independent cardioprotective effects. In an ischemic rat model, VEGF activated PI3K through a receptorindependent mechanism; however, Bcl-2 was not activated in this setting. ${ }^{123}$ Further research is warranted to determine whether pazopanib induces cardiomyocyte apoptotic pathways through inhibition of receptor tyrosine kinase/PI3K/AKT signaling.

\section{Conclusion}

Pazopanib is an effective treatment for metastatic RCC. ${ }^{35}$ The use of pazopanib will continue to increase due to the aging US population and the potential FDA approval of pazopanib for the treatment of other malignancies. As the significant cardiovascular side effect profile of pazopanib is now coming to light, it is imperative to elucidate the mechanisms underlying pazopanib-induced toxicity in order to advance the field of cardiooncology. Gaining a broader perspective of these mechanisms will allow for the development of appropriate surveillance strategies and possible diagnostic biomarkers to allow us to monitor and treat patients at a more granular level. If a patient has a cardiovascular adverse event such as MI, HF, or Torsades de Pointes while on pazopanib, we recommend immediate cessation of pazopanib and treatment according to the standard of care. Ultimately, the goal is to keep patients on these lifesaving therapies while simultaneously giving us the insight to know when to modulate or discontinue therapy prior to significant cardiac insult.

\section{Acknowledgments}

Funding

The author(s) disclosed receipt of the following financial support for the research, authorship, and/or publication of this article:This work was supported by the Robert Wood Johnson Harold Amos Faculty Development Grant and National Institutes of HealthK08 HL135437 (SAS). 


\section{References}

1. Znaor A, Lortet-Tieulent J, Laversanne M, Jemal A, Bray F. International variations and trends in renal cell carcinoma incidence and mortality. Eur Urol. 2015;67(3):519-530. [PubMed: 25449206]

2. Ridge CA, Pua BB, Madoff DC. Epidemiology and staging of renal cell carcinoma. Semin Intervent Radiol. 2014;31(1):3-8. [PubMed: 24596434]

3. Birt-Hogg-Dubé Syndrome. 2017 https://www.cancer.net/cancer-types/birt-hogg-dubé-syndrome. Accessed November 27, 2017.

4. Hicklin DJ, Ellis LM. Role of the vascular endothelial growth factor pathway in tumor growth and angiogenesis. J Clin Oncol. 2005;23(5):1011-1027. [PubMed: 15585754]

5. Jonasch E, Gao J, Rathmell WK. Renal cell carcinoma. BMJ. 2014;349:g4797. [PubMed: 25385470]

6. van der Graaf WT, Blay JY, Chawla SP, et al.; EORTC Soft Tissue and Bone Sarcoma Group; PALETTE study group. Pazopanib for metastatic soft-tissue sarcoma (PALETTE): a randomised, double-blind, placebo-controlled phase 3 trial. Lancet. 2012; 379(9829):1879-1886. [PubMed: 22595799]

7. Motzer RJ, Hutson TE, Cella D, et al. Pazopanib versus sunitinib in metastatic renal-cell carcinoma. N Engl J Med. 2013;369(8): 722-731. [PubMed: 23964934]

8. Sternberg CN, Davis ID, Mardiak J, et al. Pazopanib in locally advanced or metastatic renal cell carcinoma: results of a randomized phase III trial. J Clin Oncol. 2010;28(6):1061-1068. [PubMed: 20100962]

9. Sternberg CN, Hawkins RE, Wagstaff J, et al. A randomised, double-blind phase III study of pazopanib in patients with advanced and/or metastatic renal cell carcinoma: final overall survival results and safety update. Eur J Cancer. 2013;49(6): 1287-1296. [PubMed: 23321547]

10. Ghatalia P, Je Y, Kaymakcalan MD, Sonpavde G, Choueiri TK. QTc interval prolongation with vascular endothelial growth factor receptor tyrosine kinase inhibitors. Br J Cancer. 2015;112(2): 296-305. [PubMed: 25349964]

11. Moustafa S, Ho TH, Shah P, et al. Predictors of incipient dysfunction of all cardiac chambers after treatment of metastatic renal cell carcinoma by tyrosine kinase inhibitors. J Clin Ultrasound. 2016; 44(4):221-230. [PubMed: 26875513]

12. Qi WX, Shen Z, Tang LN, Yao Y. Congestive heart failure risk in cancer patients treated with vascular endothelial growth factor tyrosine kinase inhibitors: a systematic review and metaanalysis of 36 clinical trials. Br J Clin Pharmacol. 2014;78(4): 748-762. [PubMed: 24661224]

13. Kumar R, Knick VB, Rudolph SK, et al. Pharmacokineticpharmacodynamic correlation from mouse to human with pazopanib, a multikinase angiogenesis inhibitor with potent antitumor and antiangiogenic activity. Mol Cancer Ther. 2007;6(7): 2012-2021. [PubMed: 17620431]

14. Votrient [package insert]. East Hanover, NJ: Novartis Pharmaceuticals Corporation; 2017; https:// www.pharma.us.novartis.com/sites/www.pharma.us.novartis.com/files/votrient.pdf. Accessed August 19, 2017.

15. Welsh SJ, Fife K. Pazopanib for the treatment of renal cell carcinoma. Future Oncol. 2015;11(8): 1169-1179. [PubMed: 25832874]

16. Verkhivker GM. Exploring sequence-structure relationships in the tyrosine kinome space: functional classification of the binding specificity mechanisms for cancer therapeutics. Bioinformatics. 2007;23(15):1919-1926. [PubMed: 17537753]

17. Suttle AB, Ball HA, Molimard M, et al. Relationships between pazopanib exposure and clinical safety and efficacy in patients with advanced renal cell carcinoma. Br J Cancer. 2014;111(10): 1909-1916. [PubMed: 25349968]

18. Keisner SV, Shah SR. Pazopanib: the newest tyrosine kinase inhibitor for the treatment of advanced or metastatic renal cell carcinoma. Drugs. 2011;71(4):443-454. [PubMed: 21395357]

19. Verheijen RB, Beijnen JH, Schellens JHM, Huitema ADR, Steeghs N. Clinical pharmacokinetics and pharmacodynamics of pazopanib: towards optimized dosing. Clin Pharmacokinet. 2017;56(9): 987-997. [PubMed: 28185218] 
20. Verheijen RB, Bins S, Mathijssen RHJ, et al. Individualized pazopanib dosing: a prospective feasibility study in cancer patients. Clin Cancer Res. 2016;22(23):5738-5746. [PubMed: 27470967]

21. Aleman BM, Moser EC, Nuver J, et al. Cardiovascular disease after cancer therapy. EJC Suppl. 2014;12(1):18-28. [PubMed: 26217163]

22. Hurwitz HI, Dowlati A, Saini S, et al. Phase I trial of pazopanib in patients with advanced cancer. Clin Cancer Res. 2009;15(12): 4220-4227. [PubMed: 19509175]

23. Schutz FA, Je Y, Richards CJ, Choueiri TK. Meta-analysis of randomized controlled trials for the incidence and risk of treatment-related mortality in patients with cancer treated with vascular endothelial growth factor tyrosine kinase inhibitors. J Clin Oncol. 2012;30(8):871-877. [PubMed: 22312105]

24. Hutson TE, Davis ID, Machiels JP, et al. Efficacy and safety of pazopanib in patients with metastatic renal cell carcinoma. J Clin Oncol. 2010;28(3):475-480. [PubMed: 20008644]

25. Maitland ML, Bakris GL, Black HR, et al. Initial assessment, surveillance, and management of blood pressure in patients receiving vascular endothelial growth factor signaling pathway inhibitors. J Natl Cancer Inst. 2010;102(9):596-604. [PubMed: 20351338]

26. Kempton A, Justice C, Guo A, et al. Pazopanib for renal cell carcinoma leads to elevated mean arterial pressures in a murine model. Clin Exp Hypertens. 2017:1-10.

27. Iwamoto FM, Lamborn KR, Robins HI, et al. Phase II trial of pazopanib (GW786034), an oral multi-targeted angiogenesis inhibitor, for adults with recurrent glioblastoma (North American Brain Tumor Consortium Study 06-02). Neuro Oncol. 2010; 12(8):855-861. [PubMed: 20200024]

28. Rixe O, Billemont B, Izzedine H. Hypertension as a predictive factor of Sunitinib activity. Ann Oncol. 2007;18(6):1117. [PubMed: 17586751]

29. Rini BI, Cohen DP, Lu DR, et al. Hypertension as a biomarker of efficacy in patients with metastatic renal cell carcinoma treated with sunitinib. J Natl Cancer Inst. 2011;103(9):763-773. [PubMed: 21527770]

30. Li Y, Li S, Zhu Y, et al. Incidence and risk of sorafenib-induced hypertension: a systematic review and meta-analysis. J Clin Hypertens (Greenwich). 2014;16(3):177-185. [PubMed: 24621095]

31. Bono P, Rautiola J, Utriainen T, Joensuu H. Hypertension as predictor of sunitinib treatment outcome in metastatic renal cell carcinoma. Acta Oncol. 2011;50(4):569-573. [PubMed: 21208033]

32. Duffaud F, Sleijfer S, Litiere S, et al. Hypertension (HTN) as a potential biomarker of efficacy in pazopanib-treated patients with advanced non-adipocytic soft tissue sarcoma. A retrospective study based on European organisation for research and treatment of cancer (EORTC) 62043 and 62072 trials. Eur J Cancer. 2015; 51(17):2615-2623. [PubMed: 26321011]

33. Heath EI, Infante J, Lewis LD, Luu T, Stephenson J, Tan AR. A randomized, double-blind, placebo-controlled study to evaluate the effect of repeated oral doses of pazopanib on cardiac conduction in patients with solid tumors. Cancer Chemother Pharmacol. 2013;71(3):565-573. [PubMed: 23344712]

34. Sleijfer S, Ray-Coquard I, Papai Z, et al. Pazopanib, a multikinase angiogenesis inhibitor, in patients with relapsed or refractory advanced soft tissue sarcoma: a phase II study from the European organisation for research and treatment of cancer-soft tissue and bone sarcoma group (EORTC study 62043). J Clin Oncol. 2009; 27(19):3126-3132. [PubMed: 19451427]

35. Pinkhas D, Ho T, Smith S. Assessment of pazopanib-related hypertension, cardiac dysfunction and identification of clinical risk factors for their development. Cardiooncology. 2017;3:5. [PubMed: 29497565]

36. Hamberg P, Verweij J, Sleijfer S. (Pre-)clinical pharmacology and activity of pazopanib, a novel multikinase angiogenesis inhibitor. Oncologist. 2010;15(6):539-547. [PubMed: 20511320]

37. Yau T, Chen PJ, Chan P, et al. Phase I dose-finding study of pazopanib in hepatocellular carcinoma: evaluation of early efficacy, pharmacokinetics, and pharmacodynamics. Clin Cancer Res. 2011;17(21):6914-6923. [PubMed: 21831954]

38. Motzer RJ, Haas NB, Donskov F, et al. Randomized phase III trial of adjuvant pazopanib versus placebo after nephrectomy in patients with localized or locally advanced renal cell carcinoma. J Clin Oncol. 2017;35(35):3916-3923. [PubMed: 28902533] 
39. Izzedine H, Derosa L, Teuff G, Albiges L, Escudier B. Hypertension and angiotensin system inhibitors: impact on outcome in sunitinib-treated patients for metastatic renal cell carcinoma. Ann Oncol. 2015;26(6):1128-1133. [PubMed: 25795198]

40. Izzedine H, Ederhy S, Goldwasser F, et al. Management of hyper-tension in angiogenesis inhibitortreated patients. Ann Oncol. 2009;20(5):807-815. [PubMed: 19150949]

41. Qi WX, Lin F, Sun YJ, Tang LN, He AN, Yao Y. Incidence and risk of hypertension with pazopanib in patients with cancer: a meta-analysis. Cancer Chemother Pharmacol. 2013;71(2): 431-439. [PubMed: 23178953]

42. Wasserstrum Y, Kornowski R, Raanani P, Leader A, Pasvolsky O, Iakobishvili Z. Hypertension in cancer patients treated with anti-angiogenic based regimens. Cardio-Oncology. 2015;1(1):6.

43. Li W, Croce K, Steensma DP, McDermott DF, Ben-Yehuda O, Moslehi J. Vascular and metabolic implications of novel targeted cancer therapies: focus on kinase inhibitors. J Am Coll Cardiol. 2015;66(10):1160-1178. [PubMed: 26337996]

44. Kappers MH, van Esch JH, Sluiter W, Sleijfer S, Danser AH, van den Meiracker AH. Hypertension induced by the tyrosine kinase inhibitor sunitinib is associated with increased circulating endothelin-1 levels. Hypertension. 2010;56(4):675-681. [PubMed: 20733093]

45. Schalcher C, Cotter G, Reisin L, et al. The dual endothelin receptor antagonist tezosentan acutely improves hemodynamic parameters in patients with advanced heart failure. Am Heart J. 2001; 142(2):340-349. [PubMed: 11479476]

46. Torre-Amione G, Durand JB, Nagueh S, Vooletich MT, Kobrin I, Pratt C. A pilot safety trial of prolonged $(48 \mathrm{~h})$ infusion of the dual endothelin-receptor antagonist tezosentan in patients with advanced heart failure. Chest. 2001;120(2):460-466. [PubMed: 11502644]

47. Schorlemmer A, Matter ML, Shohet RV. Cardioprotective signaling by endothelin. Trends Cardiovasc Med. 2008;18(7):233-239. [PubMed: 19232951]

48. Banfor PN, Franklin PA, Segreti JA, et al. ETA receptor blockade with atrasentan prevents hypertension with the multitargeted tyrosine kinase inhibitor ABT-869 in telemetry-instrumented rats. J Cardiovasc Pharmacol. 2009;53(2):173-178. [PubMed: 19188829]

49. Maruyama K, Mori Y, Murasawa S, et al. Interleukin-1 beta upregulates cardiac expression of vascular endothelial growth factor and its receptor KDR/flk-1 via activation of protein tyro-sine kinases. J Mol Cell Cardiol. 1999;31(3):607-617. [PubMed: 10198191]

50. Giordano FJ, Gerber HP, Williams SP, et al. A cardiac myocyte vascular endothelial growth factor paracrine pathway is required to maintain cardiac function. Proc Natl Acad Sci U S A. 2001; 98(10):5780-5785. [PubMed: 11331753]

51. Gerber HP, McMurtrey A, Kowalski J, et al. Vascular endothelial growth factor regulates endothelial cell survival through the phosphatidylinositol 3'-kinase/Akt signal transduction pathway. Requirement for Flk-1/KDR activation. J Biol Chem. 1998; 273(46):30336-30343. [PubMed: 9804796]

52. Inai T, Mancuso M, Hashizume $\mathrm{H}$, et al. Inhibition of vascular endothelial growth factor (VEGF) signaling in cancer causes loss of endothelial fenestrations, regression of tumor vessels, and appearance of basement membrane ghosts. Am J Pathol. 2004; 165(1):35-52. [PubMed: 15215160]

53. Lee $\mathrm{S}$, Chen TT, Barber CL, et al. Autocrine VEGF signaling is required for vascular homeostasis. Cell. 2007;130(4):691-703. [PubMed: 17719546]

54. Chimenti I, Smith RR, Li TS, et al. Relative roles of direct regeneration versus paracrine effects of human cardiosphere-derived cells transplanted into infarcted mice. Circ Res. 2010;106(5): 971980. [PubMed: 20110532]

55. Ruixing Y, Dezhai Y, Hai W, Kai H, Xianghong W, Yuming C. Intramyocardial injection of vascular endothelial growth factor gene improves cardiac performance and inhibits cardiomyocyte apoptosis. Eur J Heart Fail. 2007;9(4):343-351. [PubMed: 17251059]

56. Xu XH, Xu J, Xue L, Cao HL, Liu X, Chen YJ. VEGF attenuates development from cardiac hypertrophy to heart failure after aortic stenosis through mitochondrial mediated apoptosis and cardiomyocyte proliferation. J Cardiothorac Surg. 2011;6:54. [PubMed: 21496294]

57. Levy BI, Ambrosio G, Pries AR, Struijker-Boudier HA. Micro-circulation in hypertension: a new target for treatment? Circulation. 2001;104(6):735-740. [PubMed: 11489784] 
58. Hara A, Wada T, Furuichi K, et al. Blockade of VEGF accelerates proteinuria, via decrease in nephrin expression in rat crescentic glomerulonephritis. Kidney Int. 2006;69(11):1986-1995. [PubMed: 16641924]

59. Eremina V, Jefferson JA, Kowalewska J, et al. VEGF inhibition and renal thrombotic microangiopathy. N Engl J Med. 2008; 358(11):1129-1136. [PubMed: 18337603]

60. Izzedine H, Rixe O, Billemont B, Baumelou A, Deray G. Angio-genesis inhibitor therapies: focus on kidney toxicity and hyper-tension. Am J Kidney Dis. 2007;50(2):203-218. [PubMed: 17660022]

61. Zhu X, Wu S, Dahut WL, Parikh CR. Risks of proteinuria and hypertension with bevacizumab, an antibody against vascular endothelial growth factor: systematic review and meta-analysis. Am J Kidney Dis. 2007;49(2):186-193. [PubMed: 17261421]

62. Robinson ES, Khankin EV, Karumanchi SA, Humphreys BD. Hypertension induced by vascular endothelial growth factor signaling pathway inhibition: mechanisms and potential use as a biomarker. Semin Nephrol. 2010;30(6):591-601. [PubMed: 21146124]

63. Veronese ML, Mosenkis A, Flaherty KT, et al. Mechanisms of hypertension associated with BAY 43-9006. J Clin Oncol. 2006; 24(9):1363-1369. [PubMed: 16446323]

64. Kitagawa D, Yokota K, Gouda M, et al. Activity-based kinase profiling of approved tyrosine kinase inhibitors. Genes Cells. 2013;18(2):110-122. [PubMed: 23279183]

65. Brell JM. Prolonged QTc interval in cancer therapeutic drug development: defining arrhythmic risk in malignancy. Prog Cardiovasc Dis. 2010;53(2):164-172. [PubMed: 20728704]

66. Israel CW. Mechanisms of sudden cardiac death. Indian Heart J. 2014;66(suppl 1):S10-S17. [PubMed: 24568819]

67. Strevel EL, Ing DJ, Siu LL. Molecularly targeted oncology therapeutics and prolongation of the QT interval. J Clin Oncol. 2007; 25(22):3362-3371. [PubMed: 17664484]

68. Schmidinger M, Zielinski CC, Vogl UM, et al. Cardiac toxicity of sunitinib and sorafenib in patients with metastatic renal cell carcinoma. J Clin Oncol. 2008;26(32):5204-5212. [PubMed: 18838713]

69. Bello CL, Mulay M, Huang X, et al. Electrocardiographic characterization of the QTc interval in patients with advanced solid tumors: pharmacokinetic-pharmacodynamic evaluation of sunitinib. Clin Cancer Res. 2009;15(22):7045-7052. [PubMed: 19903787]

70. Shah RR, Morganroth J, Shah DR. Cardiovascular safety of tyrosine kinase inhibitors: with a special focus on cardiac repolarisation (QT interval). Drug Saf. 2013;36(5):295-316. [PubMed: 23620167]

71. Akman T, Erbas O, Akman L, Yilmaz AU. Prevention of pazopanib-induced prolonged cardiac repolarization and proar-rhythmic effects. Arq Bras Cardiol. 2014;103(5):403-409. [PubMed: 25229355]

72. Lenihan DJ, Kowey PR. Overview and management of cardiac adverse events associated with tyrosine kinase inhibitors. Oncologist. 2013;18(8):900-908. [PubMed: 23918069]

73. Ahmad K, Dorian P. Drug-induced QT prolongation and proarrhythmia: an inevitable link? Europace. 2007;9(suppl 4): iv16-iv22. [PubMed: 17766320]

74. Dy GK, Adjei AA. Understanding, recognizing, and managing toxicities of targeted anticancer therapies. CA Cancer J Clin. 2013;63(4):249-279. [PubMed: 23716430]

75. Anon. Search for drugs that prolong QT \& induce Torsades de Pointes (TdP). CredibleMeds: Quicksearch. 2017 https://www.crediblemeds.org/index.php/drugsearch. Accessed November 5, 2017.

76. Gril B, Palmieri D, Qian Y, et al. Pazopanib reveals a role for tumor cell B-Raf in the prevention of HER2+ breast cancer brain metastasis. Clin Cancer Res. 2011;17(1):142-153. [PubMed: 21081656]

77. Kumar R, Crouthamel MC, Rominger DH, et al. Myelosuppression and kinase selectivity of multikinase angiogenesis inhibitors. Br J Cancer. 2009;101(10):1717-1723. [PubMed: 19844230]

78. Muslin AJ. Role of raf proteins in cardiac hypertrophy and cardiomyocyte survival. Trends Cardiovasc Med. 2005;15(6): 225-229. [PubMed: 16182133] 
79. Bronte E, Bronte G, Novo G, et al. What links BRAF to the heart function? New insights from the cardiotoxicity of BRAF inhibitors in cancer treatment. Oncotarget. 2015;6(34):35589-35601. [PubMed: 26431495]

80. Yamaguchi O, Watanabe T, Nishida K, et al. Cardiac-specific disruption of the c-raf-1 gene induces cardiac dysfunction and apoptosis. J Clin Invest. 2004;114(7):937-943. [PubMed: 15467832]

81. Pakladok T, Hosseinzadeh Z, Almilaji A, et al. Up-regulation of hERG K(+) channels by B-RAF. PLoS One. 2014;9(1):e87457. [PubMed: 24475291]

82. Ambrosy AP, Fonarow GC, Butler J, et al. The global health and economic burden of hospitalizations for heart failure: lessons learned from hospitalized heart failure registries. $\mathrm{J}$ Am Coll Cardiol. 2014;63(12):1123-1133. [PubMed: 24491689]

83. Cook C, Cole G, Asaria P, Jabbour R, Francis DP. The annual global economic burden of heart failure. Int J Cardiol. 2014; 171(3):368-376. [PubMed: 24398230]

84. Liao L, Allen LA, Whellan DJ. Economic burden of heart failure in the elderly. Pharmacoeconomics. 2008;26(6):447-462. [PubMed: 18489197]

85. O'Connell JB. The economic burden of heart failure. Clin Cardiol. 2000;23(3 suppl):III6-II10. [PubMed: 10754775]

86. Go AS, Mozaffarian D, Roger VL, et al. Heart disease and stroke statistics-2014 update: a report from the American Heart Association. Circulation. 2014;129(3):e28-e292. [PubMed: 24352519]

87. Roger VL, Go AS, Lloyd-Jones DM, et al. Executive summary: heart disease and stroke statistics -2012 update: a report from the American Heart Association. Circulation. 2012;125(1):188-197. [PubMed: 22215894]

88. Blecker S, Paul M, Taksler G, Ogedegbe G, Katz S. Heart failure-associated hospitalizations in the United States. J Am Coll Cardiol. 2013;61(12):1259-1267. [PubMed: 23500328]

89. Alla F, Zannad F, Filippatos G. Epidemiology of acute heart failure syndromes. Heart Fail Rev. 2007;12(2):91-95. [PubMed: 17450426]

90. Heidenreich PA, Albert NM, Allen LA, et al. Forecasting the impact of heart failure in the United States: a policy statement from the American Heart Association. Circ Heart Fail. 2013; 6(3):606619. [PubMed: 23616602]

91. Farmakis D, Stafylas P, Giamouzis G, Maniadakis N, Parissis J. The medical and socioeconomic burden of heart failure: a comparative delineation with cancer. Int J Cardiol. 2016;203:279-281. [PubMed: 26519686]

92. Sivendran S, Liu Z, Portas LJ, Jr, et al. Treatment-related mortality with vascular endothelial growth factor receptor tyrosine kinase inhibitor therapy in patients with advanced solid tumors: a meta-analysis. Cancer Treat Rev. 2012;38(7):919-925. [PubMed: 22651902]

93. Pandey M, Gandhi S, George S. Heart failure: a paraneoplastic manifestation of renal cell carcinoma-reversed with pazopanib. Clin Genitourin Cancer. 2017;15(5):e835-e837. [PubMed: 28410910]

94. Abe K, Yamamoto N, Hayashi K, et al. Balancing prolonged survival with QoL using low-dose pazopanib maintenance: a comparison with the PALETTE study. Anticancer Res. 2016; 36(6): 2893-2897. [PubMed: 27272802]

95. Groarke JD, Choueiri TK, Slosky D, Cheng S, Moslehi J. Recognizing and managing left ventricular dysfunction associated with therapeutic inhibition of the vascular endothelial growth factor signaling pathway. Curr Treat Options Cardiovasc Med. 2014; 16(9):335. [PubMed: 25099086]

96. Hunt SA, Abraham WT, Chin MH, et al. 2009 Focused update incorporated into the ACC/AHA 2005 guidelines for the diagnosis and management of heart failure in adults a report of the American college of cardiology foundation/American heart association task force on practice guidelines developed in collaboration with the international society for heart and lung transplantation. J Am Coll Cardiol. 2009;53(15):e1-e90. [PubMed: 19358937]

97. Geyer H, Caracciolo G, Abe H, et al. Assessment of myocardial mechanics using speckle tracking echocardiography: fundamentals and clinical applications. J Am Soc Echocardiogr. 2010; 23(4): 351-369; quiz 453-355. [PubMed: 20362924]

98. Thavendiranathan P, Poulin F, Lim K-D, Plana JC, Woo A, Marwick TH. Use of myocardial strain imaging by echocardiography for the early detection of cardiotoxicity in patients during and after 
cancer chemotherapy: a systematic review. J Am Coll Cardiol. 2014;63(25 part A):2751-2768. [PubMed: 24703918]

99. Baird A, Esch F, Mormede P, et al. Molecular characterization of fibroblast growth factor: distribution and biological activities in various tissues. Recent Prog Horm Res. 1986;42:143-205. [PubMed: 3526451]

100. Lieu C, Heymach J, Overman M, Tran H, Kopetz S. Beyond VEGF: inhibition of the fibroblast growth factor pathway and antiangiogenesis. Clin Cancer Res. 2011;17(19):6130-6139. [PubMed: 21953501]

101. Cilvik SN, Wang JI, Lavine KJ, et al. Fibroblast growth factor receptor 1 signaling in adult cardiomyocytes increases contractility and results in a hypertrophic cardiomyopathy. PLoS One. 2013;8(12):e82979. [PubMed: 24349409]

102. Izumiya Y, Shiojima I, Sato K, Sawyer DB, Colucci WS, WalshK. Vascular endothelial growth factor blockade promotes the transition from compensatory cardiac hypertrophy to failure in response to pressure overload. Hypertension. 2006;47(5): 887-893. [PubMed: 16567591]

103. Levy BI. Microvascular plasticity and experimental heart failure. Hypertension. 2006;47(5):827829. [PubMed: 16567590]

104. Yue X, Lin X, Yang T, et al. Rnd3/RhoE modulates hypoxiainducible factor 1alpha/vascular endothelial growth factor signaling by stabilizing hypoxia-inducible factor 1alpha and regulates responsive cardiac angiogenesis. Hypertension. 2016; 67(3):597-605. [PubMed: 26781283]

105. Chintalgattu V, Ai D, Langley RR, et al. Cardiomyocyte PDGFR-beta signaling is an essential component of the mouse cardiac response to load-induced stress. J Clin Invest. 2010; 120(2): 472-484. [PubMed: 20071776]

106. Chintalgattu V, Rees ML, Culver JC, et al. Coronary microvascular pericytes are the cellular target of sunitinib malate-induced cardiotoxicity. Sci Transl Med. 2013;5(187):187ra69.

107. Benjamin EJ, Blaha MJ, Chiuve SE, et al. Heart disease and stroke statistics-2017 update: a report from the American Heart Association. Circulation. 2017;135(10): e146-e603. [PubMed: 28122885]

108. Monk BJ, Mas Lopez L, Zarba JJ, et al. Phase II, open-label study of pazopanib or lapatinib monotherapy compared with pazopanib plus lapatinib combination therapy in patients with advanced and recurrent cervical cancer. J Clin Oncol. 2010; 28(22):3562-3569. [PubMed: 20606083]

109. Zheng W, Seftor EA, Meininger CJ, Hendrix MJ, Tomanek RJ. Mechanisms of coronary angiogenesis in response to stretch: role of VEGF and TGF-beta. Am J Physiol Heart Circ Physiol. 2001;280(2): H909-H917. [PubMed: 11158993]

110. Blann AD. Assessment of endothelial dysfunction: focus on atherothrombotic disease. Pathophysiol Haemost Thromb. 2003;33(5-6):256-261. [PubMed: 15692226]

111. Blann AD. How a damaged blood vessel wall contributes to thrombosis and hypertension. Pathophysiol Haemost Thromb. 2003;33(5-6):445-448. [PubMed: 15692258]

112. Choy JC, Granville DJ, Hunt DW, McManus BM. Endothelial cell apoptosis: biochemical characteristics and potential implications for atherosclerosis. J Mol Cell Cardiol. 2001;33(9): 1673-1690. [PubMed: 11549346]

113. Chang HM, Moudgil R, Scarabelli T, Okwuosa TM, Yeh ETH. Cardiovascular complications of cancer therapy. J Am Coll Cardiol. 2017;70(20):2536-2551. [PubMed: 29145954]

114. Kamba T, McDonald DM. Mechanisms of adverse effects of anti-VEGF therapy for cancer. Br J Cancer. 2007;96(12): 1788-1795. [PubMed: 17519900]

115. Virag JA, Rolle ML, Reece J, Hardouin S, Feigl EO, Murry CE. Fibroblast growth factor-2 regulates myocardial infarct repair: effects on cell proliferation, scar contraction, and ventricular function. Am J Pathol. 2007;171(5):1431-1440. [PubMed: 17872976]

116. Schultz JE, Witt SA, Nieman ML, et al. Fibroblast growth factor-2 mediates pressure-induced hypertrophic response. J Clin Invest. 1999;104(6):709-719. [PubMed: 10491406]

117. Datta SR, Dudek H, Tao X, et al. Akt phosphorylation of BAD couples survival signals to the cell-intrinsic death machinery. Cell. 1997;91(2):231-241. [PubMed: 9346240] 
118. del Peso L, Gonzalez-Garcia M, Page C, Herrera R, Nunez G. Interleukin-3-induced phosphorylation of BAD through the protein kinase Akt. Science. 1997;278(5338):687-689. [PubMed: 9381178]

119. Matsui T, Tao J, del Monte F, et al. Akt activation preserves cardiac function and prevents injury after transient cardiac ischemia in vivo. Circulation. 2001;104(3):330-335. [PubMed: 11457753]

120. Moore JW, Desmond JE, Berthier NE. Adaptively timed conditioned responses and the cerebellum: a neural network approach. Biol Cybern. 1989;62(1):17-28. [PubMed: 2590676]

121. Friehs I, Barillas R, Vasilyev NV, Roy N, McGowan FX, delNido PJ. Vascular endothelial growth factor prevents apoptosis and preserves contractile function in hypertrophied infant heart. Circulation. 2006;114(1 suppl): I290-I295. [PubMed: 16820588]

122. Aoyagi T, Matsui T. Phosphoinositide-3 kinase signaling in cardiac hypertrophy and heart failure. Curr Pharm Des. 2011; 17(18):1818-1824. [PubMed: 21631421]

123. Zhou L, Ma W, Yang Z, et al. VEGF165 and angiopoietin-1 decreased myocardium infarct size through phosphatidylinositol-3 kinase and Bcl-2 pathways. Gene Ther. 2005;12(3):196-202. [PubMed: 15510173] 


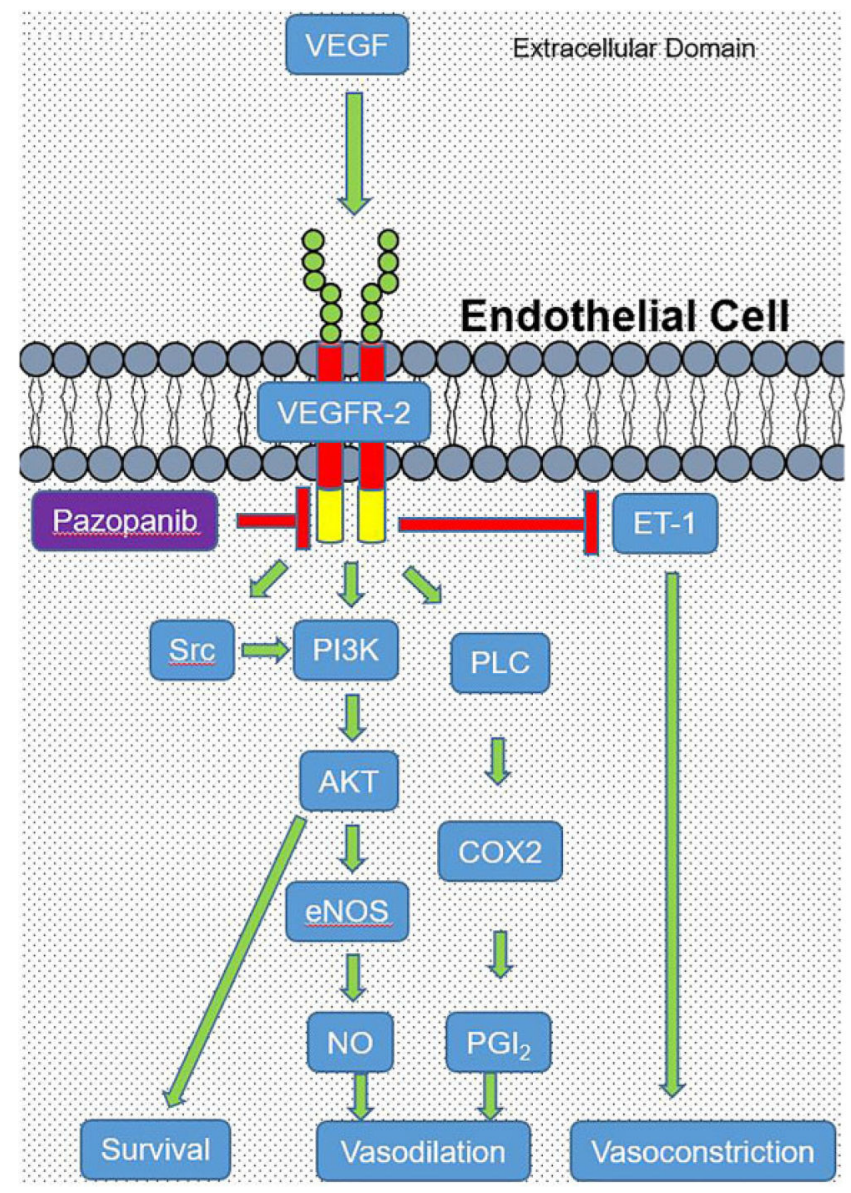

Figure 1.

Vascular endothelial growth factor (VEGF) signaling in endothelial cells is vital for cell survival and vasodilation. Vascular endothelial growth factor binds to VEGF receptor 2 (VEGFR-2) inducing a conformational change that activates Src, phosphoinositide 3-kinase (PI3K), and phospholipase C (PLC; green arrows). Phosphoinositide 3-kinase activity is a significant suppressor of apoptosis, leading to cell survival (green arrow). Additionally, $\mathrm{PI} 3 \mathrm{~K}$ is an activator of protein kinase $\mathrm{B}$ (AKT) which stimulates the production nitric oxide (NO) through activation of endothelial NO synthase (eNOS), leading to vasodilation (green arrows). Phospholipase $\mathrm{C}$ contributes to vaso-dilation through activation of cyclooxygenase 2 (COX2) which produces prostacyclin 2 ( $\mathrm{PGI}_{2}$; green arrows). Pazopanib inhibits the intracellular ATP-binding domain of VEGFR-2 (red arrow). Activation of VEGFR-2 suppresses the production of endothelin-1 (a potent vasoconstrictor; red arrow) by an unknown mechanism. 


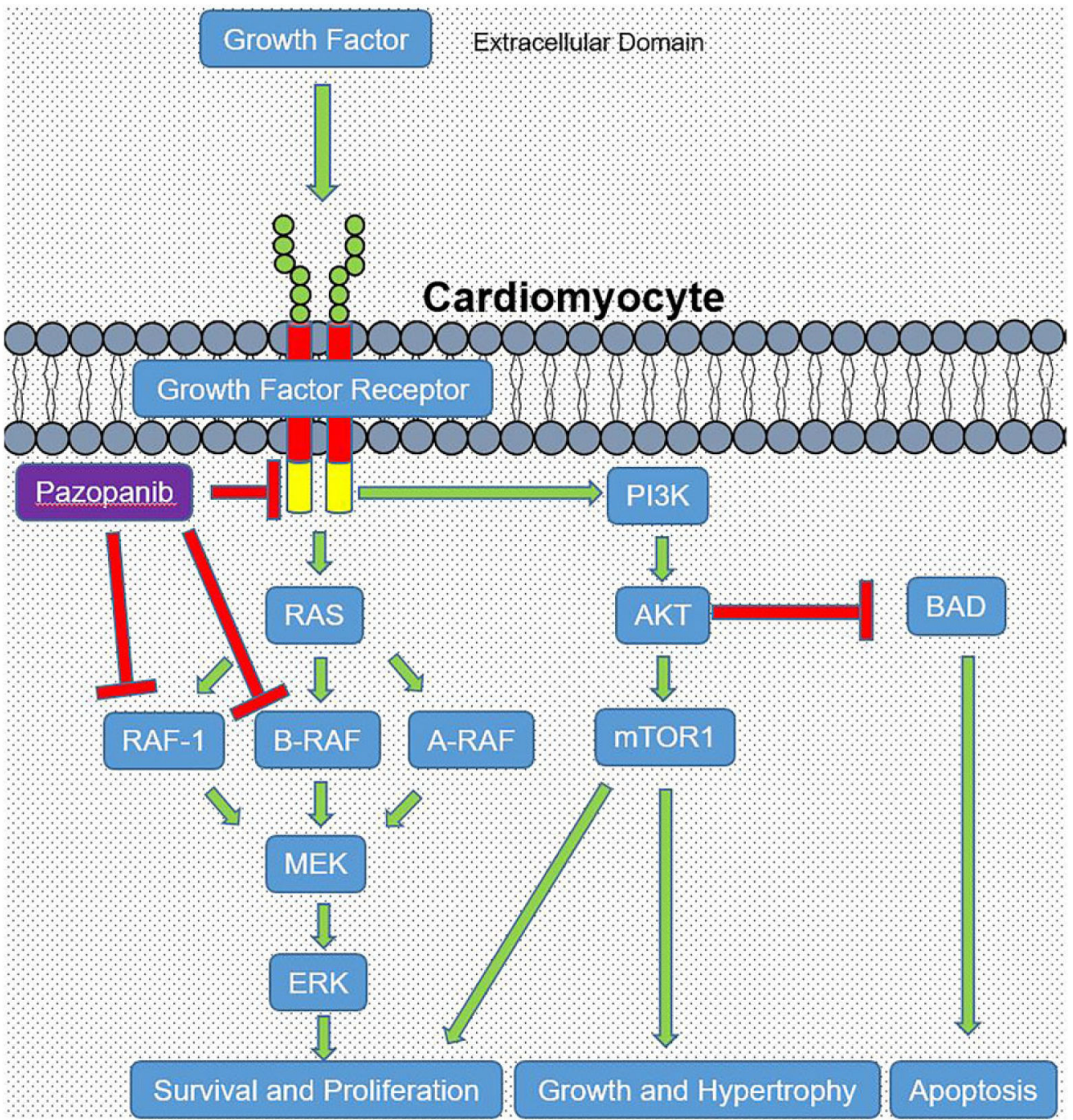

Figure 2.

Pazopanib inhibits the intracellular ATP-binding domain of many growth factors (red arrow) due to the high conservation of this domain across the kinome. Basal activity of these receptors contributes to cell survival and proliferation through the RAS/RAF/MEK/ERK and $\mathrm{PI} 3 \mathrm{~K} / \mathrm{AKT} / \mathrm{mTOR} 1$ pathways (green arrows). Protein kinase B (AKT) is a suppressor of Bcl-2 associated death promoter (BAD; red arrow), an inducer of apoptosis. Mechanistic target of rapamycin 1 (mTOR1) activity contributes to cell growth and hypertrophy (green arrow). Pazopanib also inhibits nonreceptor kinases RAF-1 and B-RAF (red arrows). 


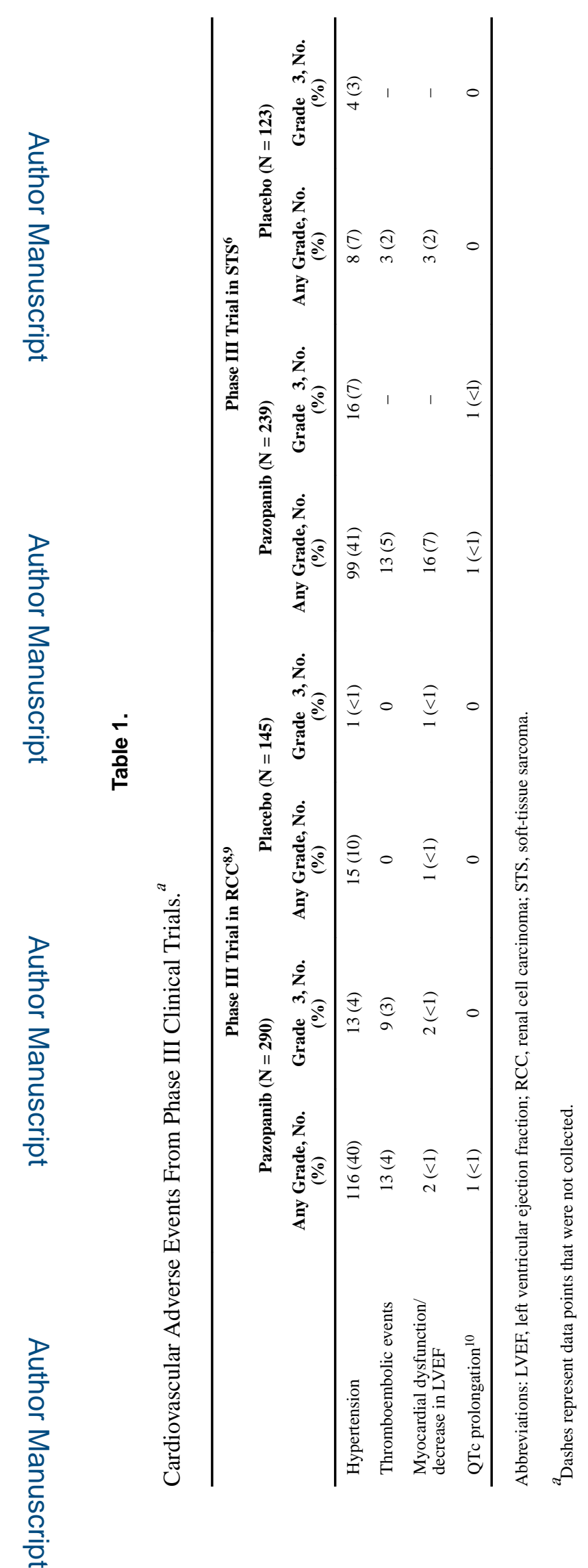

J Cardiovasc Pharmacol Ther. Author manuscript; available in PMC 2018 November 27. 